\title{
Management of Deep Gingival Recessions by Modified Coronally Advanced Tunnel Technique with Titanium Platelet Rich Fibrin Membrane or Connective Tissue Graft: 36 Months Follow-up Clinical Study
}

\author{
Cenker Zeki Koyuncuoglu (D), Esra Ercan² (D), Bilge Cansu Uzun³ (D), Mustafa Tunali² (D) Erhan Firatli ${ }^{4}$ (D) \\ ${ }^{1}$ Istanbul Aydin University, Faculty of Dentistry, Department of Periodontology, Istanbul, Turkey. \\ ${ }^{2}$ Canakkale Onsekiz Mart University, Faculty of Dentistry, Department of Periodontology, Çanakkale, Turkey. \\ ${ }^{3}$ Manisa Oral and Dental Health Center, Department of Periodontology, Manisa, Turkey. \\ ${ }^{4}$ Istanbul University, Faculty of Dentistry, Department of Periodontology, Istanbul, Turkey.
}

Correspondence Author: Cenker Zeki Koyuncuoglu

E-mail: zekikoyuncuoglu@aydin.edu.tr

Received: $10.07 .2020 \quad$ Accepted: 04.09 .2020

\begin{abstract}
Objective: The goal of the study is to evaluate the results of Titanium-Platelet Rich Fibrin (T-PRF) membrane and Connective Tissue Graft (CTG) with modified coronally advanced tunnel technique (MCATT) in treatment of deep gingival recession defects.

Methods: Twenty-one systemically healthy patients displaying 62 Miller Class I/II gingival recession defects $\geq 3.0 \mathrm{~mm}$ in depth, treated either with MCATT with CTG or with T-PRF membrane were included in this retrospective study. The periodontal parameters were assessed at baseline, and at 6 and 36 months after surgery. The percentages of the mean root coverage (MRC) and complete root coverage (CRC) were calculated.

Results: The probing depth values were decreased at 36 months according to baseline values for both groups $(p<0.05)$. Keratinized tissue (KT) was increased at 6 months according to baseline for both groups (from $1.69 \pm 0.74 \mathrm{~mm}$ to $3.61 \pm 0.67 \mathrm{~mm}$ for T-PRF; and $3.40 \pm 1.60 \mathrm{~mm}$ to 4.52 \pm 2.33 for CTG). The 36th month measurement of KT showed an increase in the T-PRF group compared to the 6th month measurement, while the CTG group showed a significant decrease $(3.86 \pm 0.76 \mathrm{~mm}$ and $2.76 \pm 1.45 \mathrm{~mm}$, respectively). The CRC ratios were $80 \%$ and $56 \%$ at 6 and 36 months, respectively for the CTG group. However, this ratio remained the same (64.86\%) for the T-PRF group. There was statistically significant difference between CRC ratios of both groups at 36 months $(p<0.05)$.
\end{abstract}

Conclusion: T-PRF membrane with MCATT procedure is as predictable as CTG with MCATT for management of deep gingival recessions. However, future prospective studies about this topic with a split-mouth design are needed.

Keywords: Gingival recession; titanium-platelet rich fibrin; root coverage; periodontal plastic surgery

\section{INTRODUCTION}

Gingival recession (GR) is defined as exposure of the root surface due to apical migration of the gingival margin beyond the cemento-enamel junction (CEJ) (1). The exposed root surfaces are commonly incorporated with root hypersensitivity, esthetic problems, and difficulties to obtain optimal oral hygiene level (2). The main goal of plastic periodontal surgical procedures is to ensure an optimal esthetic appearance with complete root coverage (CRC), and gingival recessions have been treated by various techniques (1-3). For this purpose, the laterally advanced flap (LAF), double papilla flap (DPF) or the coronally advanced flap (CAF) was used alone or with a connective tissue graft (CTG) (4). Complete root coverage can predictably be obtained when using CAF or CAF with CTG biomaterials in single Miller Classes I and II GR (5). Additionally, a recent systematic review indicated that CAF and modifications of this technique solely or combined with CTG may give the most predictable results and improve the long-term stability in multiple adjacent gingival recessions (MAGR) (2). On the other hand, CTG harvesting is frequently associated with a prolonged surgical time, limited donor tissue, increased post-operative discomfort and the possibility of post-surgical bleeding $(6,7)$. Many attempts have been made to develop alternative materials that aim to replace CTG to improve patient acceptance and reduce patient discomfort associated with root coverage (3). Autogenous and non-autogenous materials, acellular dermal matrix, collagen matrix, plateletrich plasma, and platelet-rich fibrin (L-PRF) in combination with CAF, were used for these purposes (3,8-12).

L-PRF was developed by Choukroun et al., in France in 2001 and described as an autologous leukocyte and platelet rich biomaterial $(13,14)$. The advantages of the $L-P R F$ 
technique over the other platelet-rich products include shorter and simplified preparation, low expense and lack of a requirement for an anticoagulant or any gelling agent (14). Previous studies have demonstrated that autologous growth factors, such as Platelet Derived Growth Factor (PDGF-AB), Transforming Growth Factor (TGF), Vascular Endothelial Growth Factor (VEGF), cytokines, and healing proteins (fibrinogen, fibronectin, etc.), were released in the L-PRF $(14,15)$. L-PRF consists of a dense fibrin matrix that can be easily trimmed, adapted and sutured. In recent years, successful clinical results have been achieved with this autogenous material in GR treatment $(11,12)$. However, in the original protocol, glass or glass-coated plastic tubes are used, and the unavoidable silica contact was described as follows: The silica particles in the tube are sufficiently small for a fraction to remain pendant colloidally in parts of the L-PRF (fibrin, buffy coat, and platelet poor layers of plasma) and might reach the patient (16). The initial L-PRF method was modified by our study group in changing the structure of the tubes and used a more biocompatible material (titanium), which was named titanium-prepared platelet-rich fibrin (T-PRF) (17). The fibrin in the T-PRF samples seemed thicker and better organized than L-PRF samples. As a result, there is degradation of fibrin and release of growth factors for a longer time period (18). The results of the first clinical cases demonstrated that T-PRF combined with CAF is a safe, effective choice for treating gingival recessions (GR) without complication or significant morbidity. Therefore, the aim of this clinical study was to evaluate the effectiveness of a T-PRF combined with MCATT in treating multiple adjacent Miller Class I/II GR $\geq 3.0 \mathrm{~mm}$ in 36 months.

\section{METHODS}

The present study protocol was reviewed and approved by the Ethical Committee of the Istanbul Aydin University, Faculty of Dentistry (Reg. No: 196). The study was conducted between 2012 and 2016 in accordance with the Helsinki Declaration in 2000. Written informed consent was obtained from all patients after detailed information on the risks and benefits of the clinical investigation and associated procedures was provided.

This multicenter study was designed as a retrospective trial to evaluate the results of titanium-platelet rich fibrin membrane with modified coronally advanced tunnel technique in treatment of deep gingival recession defects. The T-PRF subjects were treated at the Periodontology Department of Istanbul Aydin University, the CTG subjects were treated at the Periodontology Department of Karadeniz Technical University. At the end of the phase I treatment (oral hygiene instructions + full mouth scaling + polishing), patient selection was based on the following criteria: maxillary/mandibular, multiple adjacent Miller Class I/II GR $\geq 3.0 \mathrm{~mm}$ in depth; complaint of esthetic problems or dental hypersensitivity; vital teeth; no caries or prosthetic restoration on the selected teeth with partially fixable enamel-cement border; no bleeding on probing at the surgical sites; and no previous surgical treatment in the recession site. These criteria were met by twenty-one systemically healthy patients. The exclusion criteria were as follows: current smoking; fixed orthodontic or removable prosthesis; root surface restorations on surgical sites; any systemic disease that might be a contraindication for periodontal surgery; and lactation or pregnancy.

Sample size calculation was provided with G Power 3.1. software (Statistical Power Analyses for Windows and Mac, Heinrich-Heine-Universität Düsseldorf, Düsseldorf, Germany). The sample size calculation was confirmed according to the previous study (19). The alpha error $=0.05$, beta error $=0.80$ and effect size $=0.35$ were selected for the required sample size. Final analysis showed that 55 samples could be adequate for the study design. However; it was averaged 60 for the possible dropouts. Since we have 62 samples for the-study design (in our data base); we used $62(37 / 25)$ teeth which is acceptable and above than the 60

Three patients not involved in the present study were used to test the reproducibility of the clinician for two sessions 24 hours apart. The intra-examiner calibrations within $1 \mathrm{~mm}$ for gingival recession and probing depth (PD) measurements $\geq$ were $90 \%$. A computer-generated randomization scheme was used by one of the authors. To hide the allocation, number-labeled opaque envelopes including the name of the assigned surgical method were used. The plaque index (PI) and gingival index (GI) were scored and the following periodontal parameters were recorded at baseline, and at 6 and 36 months after surgery using a standard periodontal probe (PCP-UNC 15, Hu Friedy, Chicago, IL, USA): GR, distance from CEJ to the gingival margin; $P D$, distance from the gingival margin to the base of the gingival sulcus; clinical attachment level (CAL), distance from CEJ to the bottom of the gingival sulcus; and keratinized tissue (KT), distance from the gingival margin to the mucogingival junction (MGJ). The Lugol's iodine solution was used for staining the mucogingival complex and KT could be assessed visually. The measurements were recorded on the mid-buccal point of teeth and rounded up to the nearest millimeter. The percentages of the mean root coverage (MRC) and complete root coverage (CRC) were calculated according to the following standard formulas:

Percentage of RC = ([preoperative GR - post-operative GR]/ pre-operative GR) x 100.

Percentage of $\mathrm{CRC}=$ (teeth with complete root coverage/all treated teeth)] 100.

The present study's primary outcome variable was the percentage of RC. The secondary outcome variables were KT and AL.

The T-PRF was prepared according to the L-PRF protocol. 10 $\mathrm{mL}$ of blood was quickly drawn from the antecubital vein of each patient's right/left arm and was transferred to the specially designed grade IV titanium sterile tubes without 
any anticoagulant. The tubes were immediately centrifuged at 2,700 rpm for 12 minutes using a table centrifuge (Hettich Universal 320, Hettich Zentrifugen, Germany) at room temperature (20). After centrifugation, the T-PRF clot (in the middle part of the tube) was removed with sterile tweezers, separated from the red blood cell base without using scissors, and placed on sterile woven gauze to release the serum slowly over 10 minutes. Then, the clot was compressed to create a constant thickness of the T-PRF membrane.

The graft width was measured to include $1 \mathrm{~mm}$ beyond the root surface defects in the recipient area. The borders of the start and finish incisions were marked after palatal anesthesia. Subepithelial connective tissue graft excluded the periosteum was removed and maintained in physiological saline. The palate was sutured with 4-0 absorbable poly (glycolide-co-lactide) synthetic sutures (Pegalak, Doğsan, Turkey) and covered with non-eugenol periodontal dressing (Voco Pac, Cuxhaven, Germany). Before placing the connective tissue in the recipient area, the fat and glandular tissues and the band-shaped epithelium on the connective tissue were removed using scissors.

After local anesthesia (Ultracain D-S forte, Hoechst Roussel, Frankfurt, Germany), root planning (using Gracey curettes: Hu-Friedy Inc., Chicago, IL, USA) of exposed root surfaces was performed to reduce convexity, and no root conditioning was used. The operation sites were prepared without any vertical releasing incisions as previously described (21). The intrasulcular incisions were made with a $15-\mathrm{C}$ blade involving affected teeth and were extended to one tooth adjacent on both sides. The mucoperiosteal flaps were raised using specially designed tunnel knifes (Helmut Zepf Medizintechnik GMBH, Eitingen-Oberflacht, Germany). The partial-thickness buccal flap was raised beyond the mucogingival junction for tension-free mobilization for coronal positioning. This part of the surgery was performed with great care to avoid flap perforation. Afterwards, T-PRF membrane or CTG was placed and gently pushed into the tunneled area with an instrument and sutured. In the final step, the flaps were positioned slightly coronally to the CEJ with vertical mattress sutures. The 5-0 absorbable poly (glycolide-co-lactide) synthetic sutures (Pegalak, Doğsan, Turkey) were used.

The patients were given a cold compress extra-orally for the first 24 hours to minimize bleeding and swelling. All patients were given an appropriate non-steroidal anti-inflammatory drug (2x550 mg naproxen sodium for the first 3 days Abdi Ibrahim, Apranax Fort, Istanbul, Turkey) and $0.2 \%$ chlorhexidine mouthwash $(3 \times 1$, for 1 minute, 2 weeks; Klorhex, Drogsan, Ankara, Turkey). Advice was given to patients to brush all teeth except those in the operated region. Sutures were removed, and the surgical wounds were gently cleansed with $0.12 \%$ chlorhexidine digluconate solution two weeks after treatment. The patients were informed to use a post-operative surgical toothbrush (Curaprox CS Surgical MegaSoft Brush) only in the surgical area for four weeks. Afterwards, plaque control was reinforced, and the modified Stillman technique was taught with an ultrasoft toothbrush (Curaprox Ultrasoft Brush CS 5460, CURADEN International, Ankara, Turkey). The patients were invited to control visits $1,3,6,12,18$, 24,30 , and 36 months after surgery. In the present study, the post-operative clinical measurements of the 6 . and 36 . months are presented.

The statistical analysis was performed using a commercially available software program (IBM Corp. Released 2013, Version 22.0. Armonk, NY, USA). The results were averaged (mean \pm standard deviation [SD]) for all clinical parameters at baseline, and at the $6^{\text {th }}$ and $36^{\text {th }}$ months. The data were not normally distributed, and non-parametric tests were performed. Friedman test was used to perform the statistical analysis. The differences between examination times were evaluated by the Wilcoxon Signed Ranks Test. Mann-Whitney $U$ test was used for the MRC differences in Miller Classes I and II. A $p$ value $<0.05$ was considered as a statistically significant difference.

\section{RESULTS}

Sixty-two recession defects in 21 patients (12 females and 9 males; mean age of the patients: 43.4) were treated, and all patients completed examinations for 36 months. There were no significant differences between the groups in terms of gender and age distribution $(p>0.05)$. Wound healing was uneventful at all operated sites (there were no postoperative complications, severe pain, post-operative bleeding or edema). No complaints of esthetic problems or dental hypersensitivity were recorded after operations and in the evaluation periods. The statistical analyses for the clinical parameters are summarized in Table 1.

The post-operative PI and GI scores at 6 and 36 months were significantly lower than the baseline records for both groups $(p<0.05)$. The probing depths values were significantly 
Table 1. Descriptive statistics of the periodontal parameters at baseline and post-surgical measurements.

\begin{tabular}{|c|c|c|c|c|c|}
\hline $\begin{array}{l}\text { Periodontal } \\
\text { Parameters }\end{array}$ & $n$ & $\begin{array}{l}\text { Baseline } \\
\text { (mean } \pm \text { SD) }\end{array}$ & $\begin{array}{l}6^{\text {th }} \text { month } \\
\text { (mean } \pm S D)\end{array}$ & $\begin{array}{l}36^{\text {th }} \text { month } \\
\text { (mean } \pm \text { SD) }\end{array}$ & $p$ \\
\hline \multicolumn{6}{|l|}{ PD (mm) } \\
\hline T-PRF & 37 & $1.19 \pm 0.29$ & $1.10 \pm 0.26$ & $1.08 \pm 0.20^{b, c}$ & $\begin{array}{l}0.141(0-1) \\
0.024(1-2) \\
0.007(0-2)\end{array}$ \\
\hline CTG & 25 & $2.01 \pm 0.59$ & $2.29 \pm 0.47$ & $1.48 \pm 0.54^{b, c}$ & $\begin{array}{l}0.130(0-1) \\
0.000(1-2) \\
0.006(0-2)\end{array}$ \\
\hline \multicolumn{6}{|l|}{$\mathrm{GR}(\mathrm{mm})$} \\
\hline T-PRF & 37 & $4.12 \pm 0.88$ & $0.30 \pm 0.45^{a}$ & $0.27 \pm 0.40^{b}$ & $\begin{array}{l}0.000(0-1) \\
0.157(1-2) \\
0.000(0-2)\end{array}$ \\
\hline CTG & 25 & $3.60 \pm 0.80$ & $0.16 \pm 0.37^{a}$ & $0.56 \pm 0.71^{b, c}$ & $\begin{array}{l}0.000(0-1) \\
0.021(1-2) \\
0.000(0-2)\end{array}$ \\
\hline \multicolumn{6}{|l|}{ KT (mm) } \\
\hline T-PRF & 37 & $1.69 \pm 0.75$ & $3.61 \pm 0.68^{a}$ & $3.86 \pm 0.76^{b, c}$ & $\begin{array}{l}0.000(0-1) \\
0.003(1-2) \\
0.000(0-2)\end{array}$ \\
\hline CTG & 25 & $3.40 \pm 1.60$ & $4.52 \pm 2.33^{a}$ & $2.76 \pm 1.45^{c}$ & $\begin{array}{l}0.034(0-1) \\
0.000(1-2) \\
0.078(0-2)\end{array}$ \\
\hline
\end{tabular}

T-PRF: Titanium Platelet Rich Fibrin; CTG: connective tissue graft; PD: probing pocket depth; GR: gingival recession; KT: keratinized tissue; SD: standard

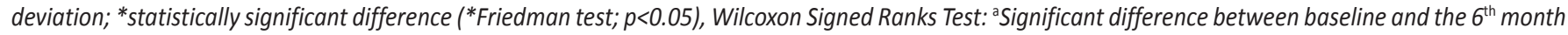
( $p<0.05)$. ${ }^{b}$ Significant difference between baseline and the $36^{\text {th }}$ month $(p<0.05)$. 'Significant difference between the $6^{\text {th }}$ and the $36^{\text {th }}$ month $(p<0.05) .0-1$ : Baseline - 6th month; 1-2: $6^{\text {th }}$ month $-36^{\text {th }}$ month; 0-2: Baseline $-36^{\text {th }}$ month.

lower at $36^{\text {th }}$ month according to baseline values for both groups $(p<0.05)$. The baseline PD value of the T-PRF group was $1.19 \pm 0.29 \mathrm{~mm}$; the $6^{\text {th }}$ and the $36^{\text {th }}$ month values were $1.10 \pm 0.26 \mathrm{~mm}$ and $1.08 \pm 0.20 \mathrm{~mm}$, respectively. This value was $2.01 \pm 0.59 \mathrm{~mm}$ at baseline, $2.29 \pm 0.47 \mathrm{~mm}$ at the $6^{\text {th }}$ month, and $1.48 \pm 0.54 \mathrm{~mm}$ at the $36^{\text {th }}$ month for the CTG group.

The baseline mean GR value of the T-PRF group was reduced from $4.12 \pm 0.88 \mathrm{~mm}$ to $0.30 \pm 0.45$ at the $6^{\text {th }}$ month $(p<0.05)$ and to $0.27 \pm 0.40 \mathrm{~mm}$ at the $36^{\text {th }}$ month $(p<0.05)$. CTG group baseline GR value $(3.60 \pm 0.80)$ was also, significantly decreased to $0.16 \pm 0.37 \mathrm{~mm}$ and to $0.56 \pm 0.71$ $\mathrm{mm}$ at the $6^{\text {th }}$ and the $36^{\text {th }}$ months, respectively $(p<0.05)$.

The KT showed a significant increase from baseline to the $6^{\text {th }}$ month (average from $1.69 \pm 0.74 \mathrm{~mm}$ to $3.61 \pm 0.67 \mathrm{~mm}$, $(p<0.05))$ T-PRF group. At the $36^{\text {th }}$ month, the KT continued to increase, but this was not significant (Table 1). The baseline KT showed an increase in the CTG group at the $6^{\text {th }}$ month (average from $3.40 \pm 1.60 \mathrm{~mm}$ to $4.52 \pm 2.33 \mathrm{~mm}(p<0.05)$ ). However, this value was significantly reduced to $2.76 \pm 1.45$ $\mathrm{mm}$ at the $36^{\text {th }}$ month $(p<0.05)$.

The root coverage $(\mathrm{RC})$ values of the groups were presented at Table 2. At the $6^{\text {th }}$ month, the $\mathrm{RC}$ values were $3.82 \pm 0.89$ $\mathrm{mm}$, and they were $3.85 \pm 0.87 \mathrm{~mm}$ at the $36^{\text {th }}$ month for the T-PRF group ( $p>0.05)$. However, there was a significant reduction of $\mathrm{RC}$ values in the CTG group at the $36^{\text {th }}$ month according to the baseline $\left(3.44 \pm 0.97 \mathrm{~mm}\right.$ at the $6^{\text {th }}$ month; $3.02 \pm 1.05 \mathrm{~mm}$ at the $36^{\text {th }}$ month $\left.(p<0.05)\right)$. There was a significant difference between the groups at the $36^{\text {th }}$ month by mean of RC $(p<0.05)$. The MRC percentages were $93.01 \%$ and $93.68 \%$ following CAF combined with T-PRF treatment at the $6^{\text {th }}$ and the $36^{\text {th }}$ months, respectively. This percentage was reduced at the CTG group at the $36^{\text {th }}$ month. The MRC percentages were $94.45 \%$ and $84.31 \%$ at the $6^{\text {th }}$ and the $36^{\text {th }}$ months, respectively. The percentage of CRC was stable for the T-PRF group (64.86\% at the $6^{\text {th }}$ and the $36^{\text {th }}$ months). However, a significant reduction of CRC was observed at the CTG group ( $80 \%$ at the $6^{\text {th }}$ month and $56 \%$ at the $36^{\text {th }}$ month). The baseline and post-operative $6^{\text {th }}$ and $36^{\text {th }}$ month results of the T-PRF and the CTG treated multiple recession-type defects were as shown in Figure 1 and 2.

Table 2. Descriptive statistics of the root coverage at the $6^{\text {th }}$ and the $36^{\text {th }}$ months.

\begin{tabular}{|lllll|}
$\mathbf{R C}$ & $\mathbf{n}$ & $\begin{array}{l}\mathbf{6}^{\text {th }} \text { month } \\
(\text { mean } \pm \text { SD) }\end{array}$ & $\begin{array}{l}\mathbf{3 6}^{\text {th }} \text { month } \\
(\text { mean } \pm \text { SD) }\end{array}$ & $\mathbf{p}$ \\
\hline T-PRF & 37 & $3.82 \pm 0.90$ & $3.85 \pm 0.87$ & 0.157 \\
\hline CTG & 25 & $3.44 \pm 0.97$ & $3.02 \pm 1,05$ & $0.005^{*}$ \\
\hline $\mathbf{p}$ & & 0.093 & 0.001 & \\
\hline
\end{tabular}

T-PRF: Titanium Platelet Rich Fibrin; CTG: connective tissue graft; $R C$ : root coverage; SD: standard deviation; *Wilcoxon signed rank test $(p<0.05)$; 

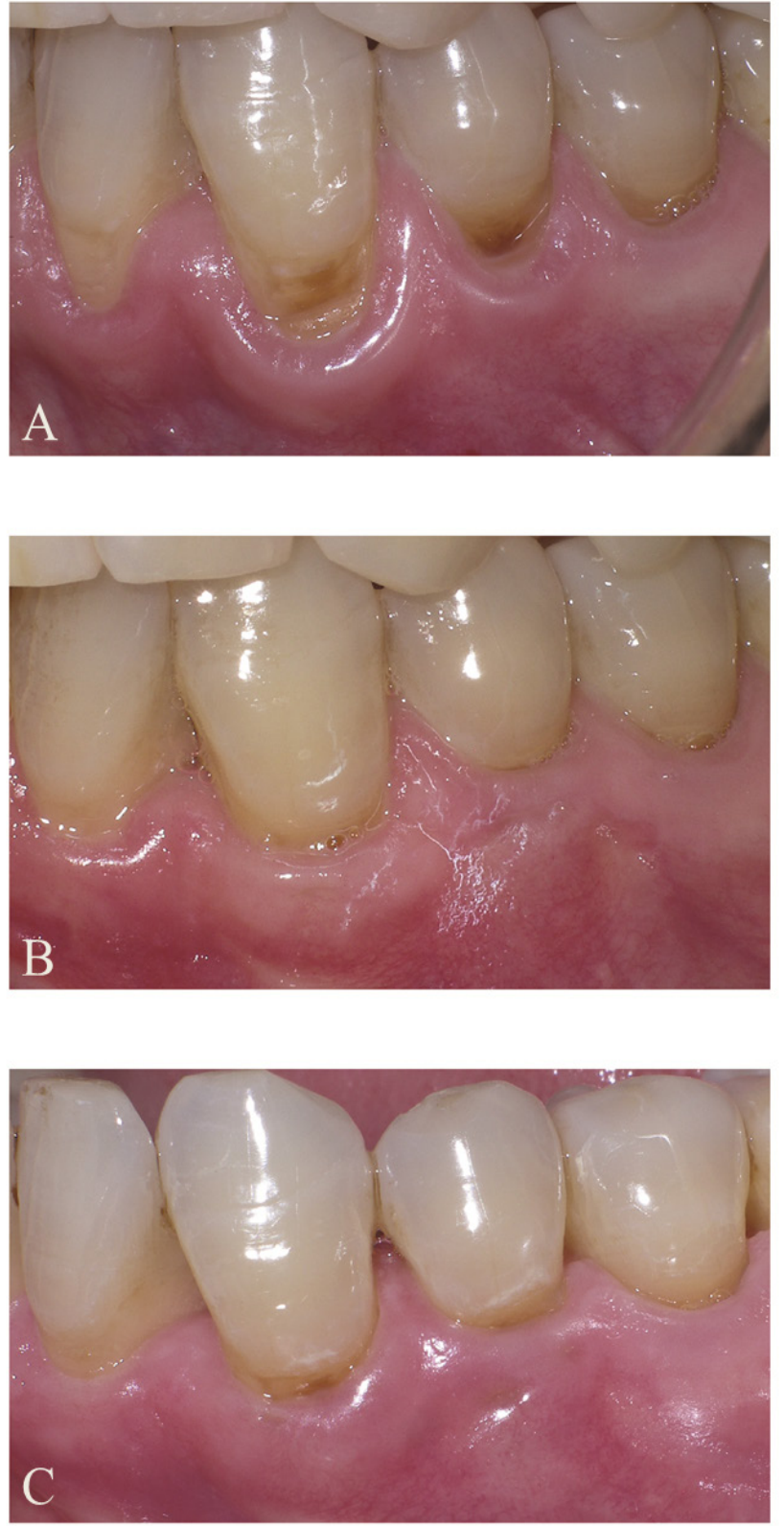

Figure 1: Results of treatment of multiple recession-type defects with Titanium Platelet Rich Fibrin on the left mandibular site of the patient. A: Preoperative view of gingival recessions; B: 6 months after surgery; $C$ : 36 months after surgery.

\section{DISCUSSION}

To the best of our knowledge, the present retrospective clinical study is the first to evaluate the effectiveness of T-PRF (as compared with CTG) in treating gingival recessions in 36 months. The present data demonstrated that this autogenous material is an effective method to cover recession defects.

Aroca et al., compared the modified coronally advanced flap (MCAF) alone with MCAF+L-PRF, and the MRC levels were $91.5 \pm 11.4 \%$ and $80.7 \pm 14.7 \%$, respectively, at 6 months. They reported no additional benefits of L-PRF combined with CAF in terms of periodontal parameters. In addition, the difference between the groups was statistically significant,
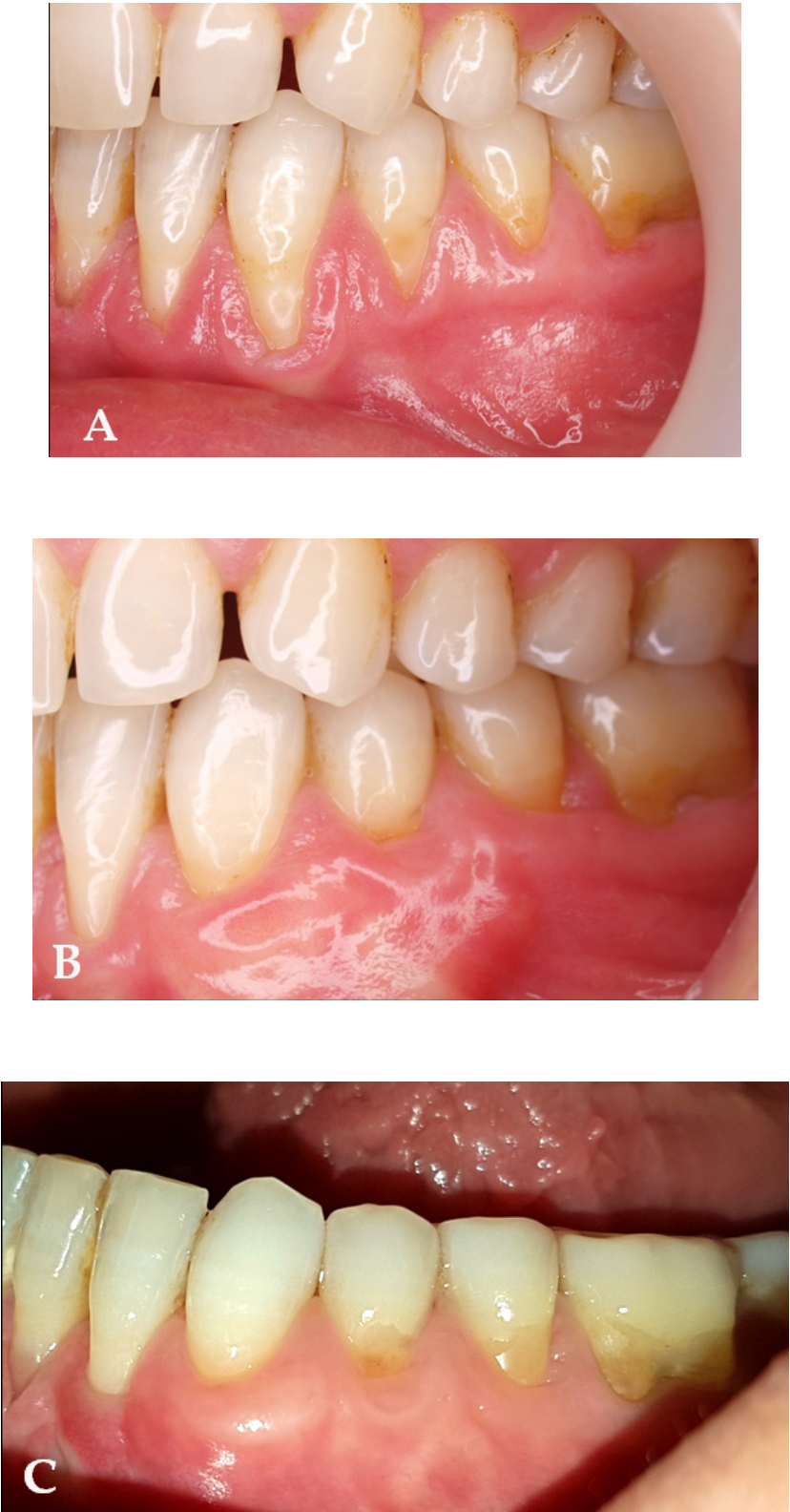

Figure 2: Results of treatment of multiple recession-type defects with connective tissue graft on the left mandibular site of the patient. A: Preoperative view of gingival recessions; B: 6 months after surgery; C: 36 months after surgery.

which favored modified CAF alone (3). This result could be explained by dehydration of the L-PRF membrane due to the inappropriate conditions (refrigerator storage) in an unidentified time period. Additionally, researchers applied only one layer of the membrane, while they must use at least two layers of membranes in gingival recession sites (22). Recent studies reported similar root coverage results with L-PRF to CTG $(11,12,23)$. Uraz et al., evaluated the CAF combined with CTG or L-PRF in multiple adjacent gingival recessions (MAGR), and similar MRC percentages were obtained (23). Tunali et al., demonstrated that the use of both 
CTG and L-PRF options were effective treatment methods in MAGR according to the 12 -month results $(77.36 \%$ and $76.63 \%$, respectively) (12). Similarly, Eren and Atilla found no statistically significant difference between CAF + L-PRF and CAF + CTG in terms of MRC in localized gingival recessions (92.7\% and $94.2 \%$, respectively) (11). However, in a recent randomized clinical trial, the combination of MCAF and L-PRF or CTG was compared. The percentage of MRC was $77.12 \%$ in the test group and $84 \%$ in the control control (24).

L-PRF is a second-generation platelet concentrate, and T-PRF is a modification of the initial method by changing the structure of the tubes with a more biocompatible titanium material (17). In this study, although 6-month follow-up period, similar results were obtained with previous studies, it was shown that T-PRF was better in RC than CTG after 36 months $(11,12,23)$. In a recent study, the clinical effects of T-PRF on human palatal mucosal wound healing were evaluated. Because of the positive results, the researchers concluded that T-PRF is a promising autogenous material for histoconduction, and it may also be preferred as an alternative to CTG in the treatment of gingival recessions (25).

The CRC values differed between studies with L-PRF $(52.2 \%$ to $75.85 \%)(3,11,22,25)$. Aroca et al., obtained a CRC of $52.2 \%$ of the sites treated with MCAF + L-PRF and $74.6 \%$ for those treated with MCAF alone (3). Similarly, in a recent study, CRC obtained in the MCAF + L-PRF and MCAF + CTG groups had values of $50 \%$ and $60 \%$ (24). However, Uraz et al., achieved superior results in the CAF + L-PRF group $(73.3 \%)$ and the CAF + CTG group (80\%) (23). The similar groups were compared in another study, and there were no statistically significant differences between the groups for the CRC percentages (72.7\% and $77.3 \%$, respectively) (11). In the present study, slightly lower CRC values were obtained. It may be related to baseline recession depth values (RC $\geq 3 \mathrm{~mm})$.

It is known that CTG obtained from the palatinal region provided keratinized tissue gain (KTG) because of the ability to induce keratinization of the epithelium (26). Chambrone et al., reported that CTG seems to be more adequate, and both $\mathrm{KT}$ and root coverage are expected (5). The KT in cases treated with L-PRF may be explained by the positive effect of proliferation of gingival and periodontal fibroblasts as a result of the influence of growth factors released from thrombocytes in the natural fibrin matrix $(11,27)$. In the present study, a statistically significant increase in KT was observed at 6 months after surgery compared to baseline in both groups $(p<0.05)$. Surprisingly, the $36^{\text {th }}$ month measurement of KT showed an increase in the T-PRF group compared to the $6^{\text {th }}$ month measurement, while the CTG group showed a significant decrease. However, Aroca et al., compared the MCAF and MCAF + L-PRF, and a significant decrease in KT values was reported at 6 months in both groups (3). In contrast to the first published L-PRF study for the treatment of gingival recession, the other studies described that a significant increase in KT was detected in
L-PRF groups at different examination times after surgery $(11,12,23)$.

The significance of gingival thickness (GT) in periodontal plastic surgeries for gingival recessions was reported in a previous review (28). It should be noted that initial GT has more influence than KT for the root coverage (29). Prior studies have evaluated the effect of L-PRF on the gingival thickness $(3,11)$. According to Aroca et al., the application of MCAF alone did not positively or negatively affect the gingival thickness at the $6^{\text {th }}$ month (3). The addition of L-PRF formed a statistically significant increase in GT $(0.3 \mathrm{~mm}$ on average). The reason for the soft tissue thickness increase was speculated to be due to the proliferative effect of growth factors in L-PRF on gingival and periodontal ligament fibroblasts or to a spacing effect of the L-PRF as a membrane. In a recent study, the application of CAF with L-PRF or CTG in localized gingival recessions was evaluated, and GT increased up to $1.5 \mathrm{~mm}$ in both groups (11). The results of this study were much better than those reported by Aroca et al. (3). The initial or post-operative GT was not measured, and this was one of the limitations of the present study. Additionally, the smaller sample size was another limitation of the study.

\section{CONCLUSION}

Within the limits of this study, the results demonstrated that T-PRF with the MCATT procedure is a safe, effective method in treating class I and II Miller gingival recessions. In addition, this procedure can be recommended to treat localized or multiple-adjacent gingival recessions without additional surgery. However, future randomized clinical trials with a split-mouth design and larger sample size are essential for evaluating the T-PRF efficiency in gingival recession treatment modalities.

\section{Acknowledgements}

The authors thank Dr. Hakan Ozdemir (Osmangazi University, Faculty of Dentistry, Department of Periodontology, Eskisehir, Turkey) for comments that greatly improved the manuscript.

\section{REFERENCES}

[1] Wennström JL, Zucchelli G. Increased gingival dimensions. A significant factor for successful outcome of root coverage procedures? A 2-year prospective clinical study. J Clin Periodontol 1996; 23:770-777.

[2] Hofmänner P, Alessandri R, Laugisch O, Aroca S, Salvi GE, Stavropoulos A, Sculean A. Predictability of surgical techniques used for coverage of multiple adjacent gingival recessions- $A$ systematic review. Quintessence Int 2012; 43:545-554.

[3] Aroca S, Keglevich T, Barbieri B, Gera I, Etienne D. Clinical evaluation of a modified coronally advanced flap alone or in combination with a platelet-rich fibrin membrane for the treatment of adjacent multiple gingival recessions: a 6-month study. J Periodontol 2009; 80:244-252.

[4] Chambrone L, Pannuti CM, Tu YK, Chambrone LA. Evidencebased periodontal plastic surgery. II. An individual data 
meta-analysis for evaluating factors in achieving complete root coverage. J Periodontol 2012; 83:477-490.

[5] Chambrone L, Sukekava F, Araújo MG, Pustiglioni FE, Chambrone LA, Lima LA. Root-coverage procedures for the treatment of localized recession-type defects: a Cochrane systematic review. J Periodontol 2010; 81:452-478.

[6] Harris RJ, Miller R, Miller LH, Harris C. Complications with surgical procedures utilizing connective tissue grafts: a follow-up of 500 consecutively treated cases. Int J Periodontics Restorative Dent 2005; 25:449-459.

[7] Zucchelli G, Mele M, Stefanini M, Mazzotti C, Mounssif I, Marzadori M, Montebugnoli L. Patient morbidity and root coverage outcome after subepithelial connective tissue and de-epithelialized grafts: a comparative randomized-controlled clinical trial. J Clin Periodontol 2010; 37:728-738.

[8] Al-Hezaimi K, Rudek I, Al-Hamdan KS, Javed F, lezzi G, Piattelli A, Wang HL. Efficacy of acellular dermal matrix and coronally advanced flaps for the treatment of induced gingival recession defects: a histomorphometric study in dogs. J Periodontol 2013; 84:1172-1179.

[9] Jepsen S, Zucchelli G, Stefanini M, de Sanctis M, Baldini N, Greven B, Heinz B, Wennström J, Cassel B, Vignoletti F, Sanz $M$. Treatment of gingival recession defects with a coronally advanced flap and a xenogeneic collagen matrix: a multicenter randomized clinical trial. J Clin Periodontol 2013; 40:82-89.

[10] Keceli HG, Sengun D, Berberoglu A, Karabulut E. Use of platelet gel with connective tissue grafts for root coverage: A randomized-controlled trial. J Clin Periodontol 2008; 35:255262.

[11] Eren G, Atilla G. Platelet-rich fibrin in the treatment of localized gingival recessions: a split-mouth randomized clinical trial. Clin Oral Investig 2014; 18:1941-1948.

[12] Tunalı M, Özdemir H, Arabacı T, Gürbüzer B, Pikdöken L, Firatli E. Clinical evaluation of autologous platelet-rich fibrin in the treatment of multiple adjacent gingival recession defects: a 12-month study. Int J Periodontics Restorative Dent 2015; 35:105-114.

[13] Choukroun J, Adda F, Schoeffler C, Vervelle A. An opportunity in perio-implantology: The PRF. Implantodontie 2001; 42:5562 (In French).

[14] Dohan Ehrenfest DM, Del Corso M, Diss A, Mouhyi J, Charrier JB. Three-dimensional architecture and cell composition of a Choukroun's platelet-rich fibrin clot and membrane. J Periodontol 2010; 81:546-555.

[15] Dohan Ehrenfest DM, Diss A, Odin G, Doglioli P, Hippolyte MP, Charrier JB. In vitro effects of Choukroun's PRF (platelet-rich fibrin) on human gingival fibroblasts, dermal prekeratinocytes, preadipocytes, and maxillofacial osteoblasts in primary cultures. Oral Surg Oral Med Oral Pathol Oral Radiol Endod 2009; 108:341-352.

[16] O'Connell SM. Safety issues associated with platelet-rich fibrin method. Oral Surg Oral Med Oral Pathol Oral Radiol Endod 2007; 103:587; author reply 587-593.
[17] Tunali M, Ozdemir H, Kucukodaci Z, Akman S, Firatli E. In vivo evaluation of titanium-prepared platelet-rich fibrin (T-PRF): a new platelet concentrate. Br J Oral Maxillofac Surg 2013; 51:438-443.

[18] Tunali M, Özdemir H, Küçükodacı Z, Akman S, Yaprak E, Toker $\mathrm{H}$, Fıratlı E. A novel platelet concentrate: titanium-prepared platelet-rich fibrin. Biomed Res Int 2014; 2014:209548.

[19] Uzun BC, Ercan E, Tunalı M.Effectiveness and predictability of titanium-prepared platelet-rich fibrin for the management of multiple gingival recessions. Clin Oral Investig 2018; 22:13451354.

[20] Dohan Ehrenfest DM, Pinto NR, Pereda A, Jiménez $P$, Corso MD, Kang BS, Nally M, Lanata N, Wang HL, Quirynen M. The impact of the centrifuge characteristics and centrifugation protocols on the cells, growth factors, and fibrin architecture of a leukocyte - and platelet-rich fibrin (L-PRF) clot and membrane. Platelets 2017; 24:1-14.

[21] Aroca S, Keglevich T, Nikolidakis D, Gera I, Nagy K, Azzi R, Etienne D. Treatment of class III multiple gingival recessions: a randomized-clinical trial. J Clin Periodontol 2010; 37:88-97.

[22] Del Corso M, Sammartino G, Dohan Ehrenfest DM. Clinical evaluation of a modified coronally advanced flap alone or in combination with a platelet-rich fibrin membrane for the treatment of adjacent multiple gingival recessions: a 6-month study. J Periodontol 2009; 80:1694-7; author reply 1697-1699.

[23] Uraz A, Sezgin Y, Yalim M, Taner IL, Cetiner D. Comparative evaluation of platelet-rich fibrin membrane and connective tissue graft in the treatment of multiple adjacent recession defects: A clinical study. J Dent Sci 2015; 10:36-45.

[24] Öncü E. The use of platelet-rich fibrin versus subepithelial connective tissue graft in treatment of multiple gingival recessions: a randomized clinical trial. Int J Periodontics Restorative Dent 2017; 37:265-271.

[25] Ustaoğlu G, Ercan E, Tunali M. The role of titanium-prepared platelet-rich fibrin in palatal mucosal wound healing and histoconduction. Acta Odontol Scand 2016; 74:558-564.

[26] Edel A. Clinical evaluation of free connective tissue grafts used to increase the width of keratinized gingiva]. J Clin Periodontol 1974; 1:185-196.

[27] Jankovic S, Aleksic Z, Klokkevold P, Lekovic V, Dimitrijevic B, Kenney EB, Camargo P. Use of platelet-rich fibrin membrane following treatment of gingival recession: a randomized clinical trial. Int J Periodontics Restorative Dent 2012; 32:41-50.

[28] Hwang D, Wang HL. Flap thickness as a predictor of root coverage: A systematic review. J Periodontol 2006; 77:16251634.

[29] Woodyard JG, Greenwell H, Hill M, Drisko C, lasella JM, Scheetz J. The clinical effect of acellular dermal matrix on gingival thickness and root coverage compared to coronally positioned flap alone. J Periodontol 2004; 75:44-56. 